\title{
The Face is the Index of the Mind: Laryngoscopy in a Multiple Endocrine Neoplasia Patient With Mucosal Involvement
}

\author{
Mojgan Rahimi ${ }^{1,} ;$;ooya Kalani ${ }^{1}$ \\ ${ }^{1}$ Department of Anesthesiology and Intensive care, Imam Khomeini Medical Center, Tehran University of Medical Sciences, Tehran, IR Iran \\ ${ }^{*}$ Corresponding author: Mojgan Rahimi, Department of Anesthesiology and Intensive care, Imam Khomeini Medical Center, Tehran University of Medical Sciences, P.O.Box: \\ 1419733141, Tehran, IR Iran. Tel: +98-2166581576, Fax:+98-2166581537, E-mail: drr_anesthesist@yahoo.com \\ Received: December 1, 2013; Revised: January 5, 2014; Accepted: June 1, 2014
}

\begin{abstract}
Introduction: Laryngeal multiple mucosal neurinomas can make intubation difficult.
Case Presentation: A16-year-old female referred to the general surgery department complaining of hoarseness and itchy throat for the past 18 months. Her symptoms had not resolved after medical treatments. After examination, the patient was admitted to the hospital and radical neck dissection was scheduled for her. Since it was assumed that lesions similar to lesions of the tongue might exist in the patient's respiratory tract, outpatient laryngoscopy and fibroscopy was performed. A yellow-white lesion was seen in front of the left-sided vocal cord. Pathological findings of the lesion confirmed neurinoma. Laryngoscopy and tube insertion were done using a GlideScope.

Conclusions: During the laryngoscopy, the neurinoma did not make any difficulty and the patient was intubated successfully.
\end{abstract}

Keywords:Multiple Endocrine Neoplasia; Laryngoscopy

\section{Introduction}

Difficult laryngoscopy and tracheal intubation occur in $1.5 \%$ to $8 \%$ of general anesthetics (1). Difficulty with tracheal intubation, particularly in patients with an unanticipated difficult airway remains a frequent cause of anesthesia-related morbidity and mortality (1). Neurofibromatosis is inherited in an autosomal dominant manner (2) with prevalence of 1 in every 210000 individuals (3). In neurofibromatosis (2B) all systems of the body might be involved because it affects both ectodermal and mesodermal tissues (4). An estimated 5\% of these patients have an intraoral manifestation of the disease (5) but neurofibroma of the larynx is a very rare condition (6). These abnormalities and lesions in airway can make intubation difficult. In order to decrease complications of breathing and patient mortality, evaluation of airway and larynx of these patients is recommended by indirect laryngoscopy before any operation.

\section{Case Presentation}

A 16-year-old female referred to the general surgery department complaining of hoarseness and itchy throat for the past 18 months. Her symptoms had not resolved after medical treatments. After examination the patient was admitted to the hospital and radical neck dissection was scheduled for her. Past medical history of the patient consisted of total thyroidectomy, six years earlier, due to thyroid medullary carcinoma. On physical examination, she had marfanoid habitus and had numerous neurinomas in her lip and tongue (Figure 1). The diagnosis of multiple endocrine neoplasia (MEN) type 2 was made based on the evidence and past history. During physical examination two lymph nodes were detected on the right side of her neck and posterior cervical plexus, respectively. The first lymph node was firm and mobile and sized $1.5 \times 2 \mathrm{~cm}$ and the other was fixed and sized $1 \times 1 \mathrm{~cm}$.

Magnetic resonance imaging (MRI) revealed bilateral cervical lymphadenopathy, which resulted in laryngeal deformity. Airway examination showed that the mouth opening was 3 fingers; thyromental distance was $80 \mathrm{~mm}$ and a mallampati class II. Neck movement and the teeth were normal. Patient's vital signs were stable before anesthesia. Since lesions similar to those observed in the lip and tongue were suspected to exist in the respiratory tract including the larynx, outpatient laryngoscopy and fibroscopy were done. A yellow-white lesion was seen in front of the left-sided vocal cord (Figure 2).

Pathological examination of the lesion confirmed neurinoma. For pre-medication fentanyl $2 \mu \mathrm{g} / \mathrm{kg}$ and midazolam $0.03 \mathrm{mg} / \mathrm{kg}$ were used. Then, $4 \mathrm{mg} / \mathrm{kg}$ sodium thiopental was administered and $1 \mathrm{mg} / \mathrm{kg}$ succinylcholine was used as the relaxant. Anesthesia was maintained with isoflurane $1 \%$ and atracurium during surgery. Laryngoscopy and tube insertion were done using a GlideScope (Saturn Biomedical inc. Canada). This configuration provides a view that is usually superior to that obtained with a conventional laryngoscope due to image magnification. 


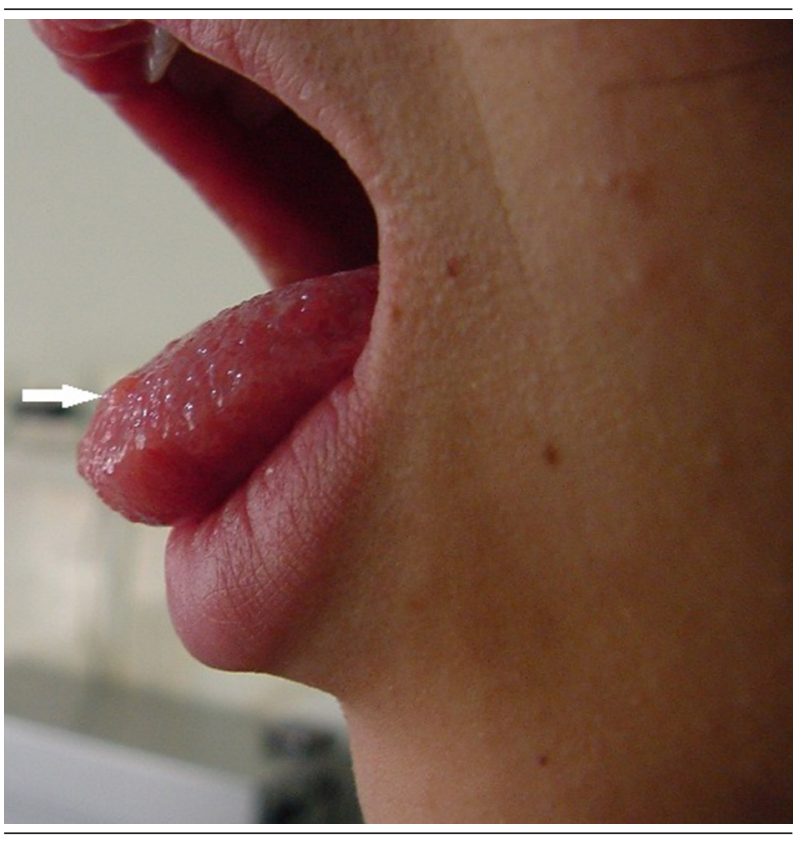

Figure 1. Numerous Neurinomas on her Lip and Tongue

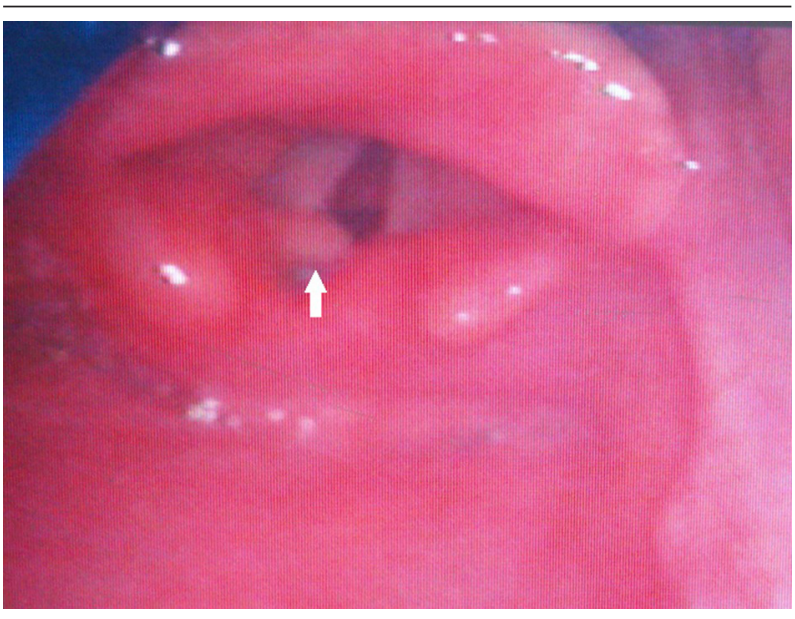

Figure 2. A Yellow-White Lesion Seen in Front of the Left-Sided Vocal Cord

During laryngoscopy the above-mentioned neurinoma did not make any difficulty and the patient was intubated successfully with tracheal tube (size 7) and a Cormack-Lehane laryngoscopic view of II. At the end of surgery, anesthesia reversal was achieved by injecting neostigmine $0.04 \mathrm{mg} / \mathrm{kg}$ and atropine $0.02 \mathrm{mg} / \mathrm{kg}$. After awakening and spontaneous breathing, the patient was extubated and was transferred to the ICU where she stayed for one day. Then she was discharged with a good general condition.

\section{Discussion}

No problem was faced during laryngoscopy and intubation, due to prior indirect laryngoscopy and small size lesion in the larynx. It should be taken in to consideration that diagnosis of neurofibromatosis is not always definite and the patient is sometimes referred for problems other than neurofibromatosis. In such cases, the anesthesiologist only notices the neurofibroma lesions in the skin, face or tongue while they are not aware of the laryngeal involvement. In one patient with tongue neurofibroma, airway obstruction was reported and the patient was subjected to an emergency tracheostomy (7).

In fact, oral neurinoma can be an alarming sign for the anesthesiologist because these neurinomas are likely to exist in lower parts of the airway. In addition a difficult airway has been reported in patients with cervical spine involvement and painless dislocation of cervical vertebra (8). Difficult airway and intubation due to large lesions can occur, thus evaluation of patient's airway with indirect laryngoscopy and radiographic examination of the neck before administration of anesthetic drugs especially muscle relaxants is recommended (8).

\section{Authors' Contributions}

Study concept and design, acquisition of data, analysis and interpretation of data, and drafting of the manuscript: Dr Pooya Kalani. Study supervision: Dr Mojgan Rahimi.

\section{References}

1. Crosby ET, Cooper RM, Douglas MJ, Doyle DJ, Hung OR, Labrecque $\mathrm{P}$, et al. The unanticipated difficult airway with recommendations for management. Can J Anaesth.1998;45(8):757-76.

2. Evans DG, Huson SM, Donnai D, Neary W, Blair V, Teare D, et al A genetic study of type 2 neurofibromatosis in the United Kingdom. I. Prevalence, mutation rate, fitness, and confirmation of maternal transmission effect on severity. J Med Genet. 1992;29(12):841-6.

3. Huson SM. What level of care for the neurofibromatoses? Lancet. 1999;353(9159):1114-6.

4. Hirsch NP, Murphy A, Radcliffe JJ. Neurofibromatosis: clinical presentations and anaesthetic implications. Br J Anaesth. 2001;86(4):555-64.

5. Baden E, Pierce HE, Jackson WF. Multiple neurofibromatosis with oral lesions; review of the literature and report of a case. Oral Surg Oral Med Oral Pathol. 1955;8(3):263-80.

6. Donaldson MC, Ellison LH, Ramsby GR. Hypertension from iso lated thoracic aortic coarctation associated with neurofibromatosis. J Pediatr Surg. 1985;20(2):169-71.

7. Crozier WC. Upper airway obstruction in neurofibromatosis. Anaesthesia.1987;42(11):1209-11.

8. Lovell AT, Alexander R, Grundy EM. Silent, unstable, cervical spine injury in multiple neurofibromatosis. Anaesthesia. 1994;49(5):453-4. 